\title{
O ser professor em contínua construção
}

\author{
The act of being teacher in continuing construction
}

El ser professor en continua construcción

DENISE DALPIAZ ANTUNES*
HELENARA PLASZEWSKI**

\begin{abstract}
RESUMO
O texto objetiva contribuir com algumas reflexões acerca da formação contínua de professores, além da formação inicial, na proposta paradigmática de educação continuada ao longo da vida pessoal do docente. Apresenta construtos teóricos que apontam para as possibilidades de autoformação em busca do autoconhecimento, dos profissionais que constituem a base da formação humana de outros seres humanos. Além disso, o artigo apresenta um modelo de educação continuada considerado eficiente pela abordagem de necessidade de atualização de formação, baseado em oficinas pedagógicas, com trabalho cooperativo entre os pares. Uma proposta de governo que, muito embora não tenha se constituído como possibilidade de política pública de formação de professores, no Brasil, acaba por ressaltar a falta de incentivos e de consciência social pela profissão do Ser Professor. Além de apontar a possiblidade de renovadas práticas educativas a partir de formações no locus escolar, conforme o destaque da grande maioria dos professores participantes.
\end{abstract}

Palavras-chave: Formação continuada. Educação contínua. Profissão docente. Pnem.

\begin{abstract}
This text aims to contribute with some reflections about the continuing formation of teachers, in addition to the initial formation, in the paradigmatic proposal of continuing education, throughout the personal life of the teacher, presenting theoretical constructs that point to so many possibilities of self - formation in search of self-knowledge of the professionals that form the basis of the human formation of other human beings. In addition, the article presents a continuing education model considered to be efficient by the need for refresher training, based on pedagogical workshops with cooperative work among peers. A proposal for a government that, although it has not constituted itself as a possibility of public policy of teacher formation in Brazil, which ends up emphasizing the lack of incentives and social awareness for the profession of Being Teacher, pointed out the possibility of renewed practices based on formations in the school locus, as highlighted by the great majority of participating teachers.
\end{abstract}

Keywords: Continuing formation. Continuing education. Teacher profession.

\section{RESUMEN}

El texto objetiva contribuir con algunas reflexiones acerca de la formación continuada de profesores, bien como de la formación inicial, en la propuesta paradigmática de educación continuada a lo largo de la vida personal del docente, presentando constructos teóricos que apunten a tantas posibilidades de autoformación en busca del autoconocimiento profesional, el cual constituye la base de la formación humana de otros seres humanos. Además, el artículo, presenta un modelo de formación continuada considerado eficiente por la necesidad de actualización de formación, basado en talleres pedagógicos, con trabajo cooperativo entre los pares. Una propuesta de gobierno, que aunque no se haya constituido como posibilidad de política pública de formación de profesores, en Brasil, que ressalta en la falta de incentivos y de conciencia social por la profesión del Ser Profesor, apuntó la posibilidad de renovadas prácticas educativas a partir de formaciones en el locus escolar conforme el destaque de la gran mayoría de los profesores participantes.

Palabras clave: Formación continua. Educación continua. Profesión docente.

\footnotetext{
* Doutora e Mestre em Educação, Licenciada em Educação Física Especialista em Educação Infantil, Docente no Departamento de Ensino, na Faculdade de Educação - Universidade Federal de Pelotas - UFPel.E-mail:drdenisedalpiaz@gmail.com

**Coordenadora do Programa de Pós-Graduação em Educação - Lato Sensu da UFPel. Professora Adjunta no Departamento de Ensino, Faculdade de Educação da Universidade Federal de Pelotas. Doutora e Mestre em Educação - UFPel, Especialista em Psicologia Escolar - PUCRS. Licenciada em Pedagogia -FAPA. E-mail: helenara.ufpel@gmail.com
} 


\section{INTRODUÇÃO}

Muito embora a profissão docente ainda não seja reconhecida e valorizada, neste país, como de grande valia para a formação do ser humano, muitos professores vêm se destacando no sentido de proporcionar uma educação integral e integralizadora da construção de sujeitos mais autônomos. Trazendo propostas de ensino que cada vez mais comtemplem a tão almejada qualidade da educação, a qual todos têm direito.

Sobretudo, o professor, em qualquer ambiente educativo ou instituição de ensino formal, é ser humano único em identidade, inter-relações e construções de saberes. Em constante desenvolvimento pessoal, ele possui valores e hábitos socioculturais, concepções e ações educativas desde a construção social à formação inicial, especialmente quanto aos modelos escolares vivenciados, que o identificam com diferenciadas características de pessoalidade.

Em sua maioria, os docentes que, desde cedo, ainda na infância, edificaram-se em busca do Ser Professor, seguem sua trajetória de vida no desenvolvimento pessoal. Perpassam a formação inicial com os primeiros referenciais da carreira, constituindo-se no dia da docência. Buscam constantemente um desenvolvimento ao longo da vida, internalizando cada vez mais o "educador", muito além de apenas professar um conhecimento: educar também para toda a vida, vida em construção.

A vida do ser humano revela-se e é revelada no dia a dia, alicerçada em cada motivo pessoal e em metas desejadas, com objetivos de vida que podem ser alcançados ou não. É constituída de significados que se estabelecem na internalização, a partir das inter-relações: das intra e inter-relações, desde o início da vida social.

Enfatiza-se que toda a caminhada profissional docente começa a se estabelecer muito antes dos referenciais acadêmicos apreendidos na formação inicial. Ou, ainda, na academia, a vontade de Ser Professor vai se configurando a partir dos desejos constituídos nas relações familiares e afetivas, nas possibilidades de ser um educador, conforme citado acima. Ou seja, anteriormente à formação específica para a profissão, para cada atuação de nível de ensino, cada professor se constitui na individualidade de vivências socioculturais, especialmente dentro do ambiente educativo de sua vivência e ação pessoal.

Assim, muito além da formação inicial, para que os ideais de constante formação ao longo da vida aconteçam de modo atualizado, contemplando as necessidades da escola, do aluno, do professor do século XXI, a formação continuada de professores requer um olhar mais abrangente epistemologicamente, no que tange às suas ações e efetivas participações. Isso indica novos conceitos, novas propostas de formação humana, fundamentados na prática reflexiva e alicerçados na práxis estabelecida pelo docente, em cada espaço educativo, especialmente no lócus escolar, indubitavelmente com suas realidades específicas a partir de tantas diversidades e adversidades dos sujeitos participantes desse meio. Para tanto, novas construções pessoais necessitam um novo paradigma de formação: uma educação continuada.

Muitos são os modelos ou propostas de formação continuada que são apresentados para os professores em diferentes níveis de ensino, em diferentes contextos sociais e em diferentes países, enfatizando cada vez mais a necessidade vital de educação permanente. Muitas dessas propostas são eficientes e eficazes quando se adaptam às necessidades dos docentes, quando são motivadoras ao ato de ensinar e ao consequente ato de aprender.

Destaca-se que muitas dessas possibilidades de formação ainda não estão concretizadas dentro da carreira docente, mesmo como um direito garantido em lei. Nem sempre motivadoras para a carreira docente, muitas vezes, representam modelos isolados que podem vislumbrar apenas o professor na docência, sem perpassar o dia a dia da sala de aula e, muito antes disso, as necessidades primeiras de cada professor.

Nesse sentido, afirma-se que na ampla diversidade sociocultural do/no ambiente educativo, bem como nas representações subjetivas de cada ser humano, inserido na instituição escolar, justificam-se exigências de educação contínua, para todos os professores, entre outras necessidades, muito além da formação inicial e dos saberes até então constituídos nas relações sociais.

Portanto, é necessário repensar e romper com os paradigmas de formação docente já estabelecidos e construir não apenas uma prática de formação com interesses e emergências de atender a demandas particulares e/ou pontuais de temáticas específicas, como mudanças de leis e novos parâmetros de ensino. Para além da atualização profissional, é urgente promover, epistemologicamente, uma nova perspectiva sobre a importância da formação contínua de educadores. O que possibilita ao profissional da educação romper com as reproduções de seu habitus social, tornando-o um construtor próprio e um mediador de tantos outros capitais culturais (BOURDIEU, 2013) que perpassarão sua trajetória; uma educação contínua ao longo da vida, uma vida em docência.

Assim, este texto tem o propósito de contribuir com algumas reflexões acerca dessa temática da formação de professores, na proposta paradigmática de educação continuada, ao longo da vida pessoal do docente. Apresenta construtos teóricos que apontam para possibilidades de autoformação em busca do autoconhecimento, dos profissionais que constituem a base da formação humana de outros seres humanos. 
Além disso, o artigo apresenta um modelo de formação continuada considerado eficiente pela abordagem de necessidade de atualização da formação, baseado em oficinas pedagógicas, com trabalho cooperativo entre os pares. Uma proposta de governo que, muito embora não tenha se constituído como possibilidade de política pública de formação de professores, no Brasil, ressaltando a falta de incentivos e de consciência social pela profissão do $\mathrm{Ser}$ Professor, apontou a possiblidade de renovadas práticas educativas a partir de formações no locus escolar. Este o destaque da grande maioria dos professores participantes.

\section{O DOCENTE E À DOCÊNCIA}

As primeiras internalizações à docência acontecem na infância e, na grande maioria das vezes, é na adultez jovem (MOSQUERA, 1987) que a decisão se concretiza, muito provavelmente no processo de formação pessoal, inicialmente na academia. Isso ocorre, especialmente, quando nesse entorno acadêmico acontecem oportunidades de vivência escolar, especialmente no início dos cursos de formação de professores, nos estágios e vivências escolares. É fundamental a experiência do exercício da profissão, muito além da sala de aula, desde o começo da formação, de modo a construir e fortalecer os vínculos à carreira, decisivamente à identificação ao panorama educacional.

Desde a formação inicial até os primeiros passos da docência, "a construção da identidade profissional também depende da cultura escolar em que o professor desenvolve seu trabalho" (MARQUESI, 2008, p. 121). No entanto, Claxton (2005, p. 21) alerta que

a aprendizagem ao longo da vida exige, por exemplo, a capacidade de pensar estrategicamente sobre o nosso próprio caminho de aprendizagem, e isso requer a autoconsciência para conhecer seus próprios objetivos, os recursos necessários para busca-lo atingi-los e suas potencialidades e fragilidades nesse aspecto. Temos que assumir a responsabilidade de ser nosso próprio treinador na aprendizagem [...].

Contudo, cabe destacar que a aprendizagem ao ato pedagógico, que advém da experiência do real contexto educativo e social, revela-se evidentemente na identidade pessoal e profissional do professor em ação. Essas construções são características das subjetividades que acompanham cada indivíduo no próprio trabalho docente, contribuindo também para a constante aprendizagem de novos saberes.

Além disso, acredita-se que "o professor é um planejador do ensino e da aprendizagem, que trabalha no sentido de dar maior produtividade, eficiência e eficácia ao processo, maximizando o desempenho do aluno"
(MIZUKAMI, 2007, p. 31-32) (grifo do autor). No sentido aqui destacado, o educador deve ir além dos parâmetros esperados pelo contexto sociocultural, de modo a registrar e afirmar uma identidade cultural aos saberes por ele apreendidos e posteriormente oportunizados aos alunos.

No sentido de aprendizagem pessoal de docentes, enfatiza-se que as primeiras relações nas instituições educativas, antes das vivências escolares de alfabetização e das primeiras concepções do aprender a aprender ${ }^{1}$, pelos modelos positivos, ou não, em sua pessoalidade, o professor vai se compondo. Ou seja, desde as primeiras experiências educativas, na educação formal, o indivíduo escolhe o modelo de educador que deseja ser: essa escolha nem sempre é consciente. Mosquera (1979, p. 13) afirma que "a formulação básica dos pensamentos e atitudes dos seres humanos decorre, evidentemente, de momentos históricos e situacionais", nos quais os sentidos pessoais estão conscientes. "O mundo íntimo se enriquece através do valor e sentido que a pessoa dá ao conteúdo do significado" (MOSQUERA, 1979, p. 13) (grifo do autor).

Isto é, mesmo sem perceber, inconscientemente muitas vezes, cada professor vai, ao longo de sua vida, internalizando conceitos e atitudes que mais tarde revelam-se-em sua ação docente, em sua concepção de ser humano entre ensinar e aprender. Contudo, todas as aprendizagens que edificam o ofício do Ser Professor são o resultado das relações sociais, que desde a infância, nos ambientes culturais, o constituem. Nóvoa (1999, p. 16) afirma que "a natureza do saber pedagógico e a relação dos professores ao saber constituem um capítulo central da história da profissão docente".

Entre desenvolvimento pessoal e aprendizagem contínua, a constituição do Ser Professor na formação inicial, indivíduo entre adultez jovem e adultez média, edifica-se na vivência pessoal, profissional. Nesse construto, Mosquera (1982, p. 95) ressalta que "o fenômeno da vida adulta se estrutura a partir, especificamente, de um fenômeno vivencial. [...]”. Isto é, o docente apresenta características próprias, sejam elas resultados das vivências pessoais, familiares, culturais e/ou educativas, ou assumidas pela significação social de suas construções e subjetividades pessoais e intencionalidades educativas. Ele pode também revelar novas aprendizagens junto do grupo, quando houver possibilidades de uma formação contínua que oportunize aprendizagens reflexivas com os pares.

Segundo Maslow (1970, p. 29),

\footnotetext{
"A educação ao longo de toda a vida baseia-se em quatro pilares: aprender a conhecer, aprender a fazer, aprender a viver juntos, aprender a ser" (DELORS, 2003, p. 101) Em todos estes, está imbricado o aprender a aprender como via de regra para a motivação pessoal voltada às aprendizagens no percurso do desenvolvimento humano.
} 
quanto mais aprendemos sobre as tendências naturais do homem, mais fácil será dizer-lhe como ser bom, como ser feliz, como ser fecundo, como respeitarse a si próprio, como amar, como preencher as suas mais altas potencialidades. Isso equivale à solução automática de muitos problemas da personalidade do futuro. A coisa a fazer, segundo me parece, é descobrir o que é que realmente somos em nosso âmago, como membros da espécie humana e como indivíduos.

Assim, Ser Professor é também ser sujeito ímpar, que está em desenvolvimento e torna-se singular na ação educativa, com ela e a partir dela. "Durante a vida toda, em cada aspecto dela, as pessoas são aprendizes. A aprendizagem ao longo da vida abrange [...] viver em novas culturas; aprender novas habilidades; [...] desenvolver uma posição com relação às questões atuais" (CLAXTON, 2005, p. 221).

Tardif (2002) também destaca que é importante compreender as relações entre tempo, trabalho e aprendizagem dos saberes profissionais dos professores: saberes esses empregados na prática educativa, emanados desta, e que sustentam as situações do dia a dia no trabalho. Todos os saberes revelam e apontam a identidade docente, além do que são efetivamente os saberes utilizados pelos professores no contexto de sua profissão. Wenger (1998, apud MARQUESI, 2008, p. 120), referindo-se à docência, alerta que "a identidade profissional é composta por diferentes dimensões e relações que é necessário integrar: a experiência pessoal, o sentimento de pertencimento a uma comunidade, a trajetória de aprendizagem e os diversos pertencimentos a grupos diferenciados".

Então, o saber profissional advém de várias fontes de saberes, oriundas da história de vida individual, da sociedade, da instituição, da formação, bem como de diferentes momentos e fases de construção profissional. Entretanto, uma parte significativa da competência do professor tem origem em sua história de vida. Por isso, os saberes dos professores são utilizados e desenvolvidos ao longo de sua carreira profissional. É exigida dos professores, ainda, uma assimilação de saberes práticos, específicos a lugares de trabalho, rotinas, valores, entre outros. Por isso, Marquesi (2008, p. 120) salienta que

grande parte da identidade profissional depende da valorização social percebida. O sentimento de perda de estima e do reconhecimento social corrói as bases da identidade profissional e reduz os vínculos entre os membros da profissão e seu senso de pertencimento a ela. Quando os objetivos da atividade docente se tornam difusos, ocorre o mesmo ao mesmo tempo, com seus sinais de identidade.

O mesmo autor também afirma que esses casos, infelizmente, são cada vez mais frequentes, em diferentes âmbitos socioculturais, e que isso vem alterando a identidade docente e contribuindo para um grande número de insatisfeitos, sentindo-se incompetentes e ineficazes na ação (MARQUESI, 2008). Ele ainda completa a ideia de que "a perda da autoestima provoca, também, a perda de sua identidade e leva, inevitavelmente, à insatisfação e ao mal-estar emocional" (MARQUESI, 2008, p. 120), acarretando um número muito grande de professores doentes.

Contudo, há que se estabelecer uma proposta pessoal de desenvolvimento e formação na carreira, a qual represente a positividade em busca da saúde, do bem-estar, com vistas à motivação intrínseca. De qualquer modo, as primeiras aprendizagens referidas ao ato de educar serão estabelecidas desde o começo da formação acadêmica, mas de maneira prática serão edificadas na práxis diária. Para Tardif (2002, p. 52), "o tempo de aprendizagem do trabalho confunde-se muitas vezes com o tempo da vida".

Nesse propósito, para além da sala de aula e muito menos distante dela, a educação contínua precisa ser, também, paradigma de vida em continuidade, pois "a formação continuada transforma-se em recurso estratégico para que as 'inovações' sejam materializadas nas salas de aula. Ou a dinâmica da formação continuada consiste em um caminho para a reapropriação da experiência adquirida, tendo em vista adequá-la com as novas situações vividas pelos docentes na atualidade", assinala Freitas (2007, p. 44).

Por fim, o professor que se encontra possivelmente na adultez jovem, primeira fase da vida adulta, com sua vitalidade e sonhos, é o adulto jovem que "está dotado dos mais fortes impulsos, os quais se manifestam tanto pela impulsividade como pelo emprego vivo de suas forças. Seu estado de espírito diante da vida alcançou, por regra geral, um elevado nível. A alegria de viver e o prazer da existência lhe fornecem perspectivas" (MOSQUERA, 1982, p. 80). Esse sujeito deve, por uma proposta ou possibilidade de autoconhecimento, utilizar-se dessas características, entre outras da adultez, as quais podem também contribuir para a construção pessoal da/na docência.

Em seguida, após esse período e não distinto deste, mas de modo intrínseco em cada ser humano, está o adulto médio, maior fase da vida adulta, ao qual cabe muitas responsabilidades e dificuldades em função dessas representações que o social lhe impõe, especialmente na consciência gerativa por outras gerações. Também o adulto médio, na sequência das transformações de desenvolvimento humano, “[...] se sente possuído pelo afã de produção e por interesses objetivos, deseja ser eficaz e ter êxito" (MOSQUERA, 1987, p. 96), características essas que também devem ser valorizadas na profissão do Ser Professor.

Sobretudo, acerca do docente com suas características, especificidades, responsabilidades e ações, entre outras, 
enfatiza-se que a formação contínua deve ser consciente, de modo a ser parte de todo momento da vida. Por tudo isso, é devido ao educador uma formação que seja contínua, que represente vida em desenvolvimento, em vivências e ações específicas da docência e para além destas, na vida integral de cada um: uma educação continuada.

\section{O DOCENTE E A FORMAÇÃo CONTÍNUA}

A formação continuada de professores vem ao longo dos tempos se efetivando como uma necessidade constante de ações, distantes de propostas pontuais, ou mesmo de momentos marcados por programas e ações distantes das realidades escolares e de educadores. Muito além das necessidades de professores e de alunos, impõe-se uma concepção de formação que seja contínua; uma educação ao longo da vida, com possibilidade de constantes aprendizagens. Nisso, revela-se a urgência paradigmática da educação continuada impreterivelmente advinda das intencionalidades e necessidades educacionais de alunos e professores, impreterivelmente alicerçada pelas realidades de subjetividades, diversidades e adversidades do lócus escolar. Por isso,

ao tratar da Formação Continuada de professores requer que tenhamos um olhar mais abrangente epistemologicamente, no que tange às suas ações e efetivas participações dos docentes. Tudo isso indica novos conceitos, novas propostas, fundamentados na prática reflexiva e alicerçados na práxis estabelecida pelo docente, em cada espaço educativo. Para tanto, novas construções pessoais que revelem novas ações entre ensinar e aprender necessitam um novo paradigma de formação: uma Educação Continuada (ANTUNES; PLASZEWSKI; DECKER; SILVA, 2017, p. 37-38).

Nesse propósito, é necessário estabelecer os objetivos e metas na escolha da vida profissional, num caminho de autoconhecimento, de propósito de vida. No entanto, essas necessidades iniciais de vivências pessoais e coletivas não são fáceis, na medida em que o ambiente escolar não consegue, muitas vezes, acolher o profissional que recém chega da academia ou, ainda, de outro ambiente profissional. Em tudo isso,

as administrações educacionais deveriam ser conscientes da importância de os professores se sentirem orgulhosos de fazerem parte da profissão docente. Não é uma tarefa simples se levamos em conta que a maioria dos professores considera que nem a sociedade nem a própria administração educacional dão a eles o devido valor. É possível, ainda, que alguns professores tenham interiorizado esse descrédito social e praticamente não se valorizem profissionalmente (MARQUESI, 2008, p. 123).
Assim, entre direitos e deveres, a formação continuada de professores deve abarcar muitas dimensões humanas e sociais, as quais perpassam o ambiente educativo. "Quando a administração educacional se preocupa com que os professores tenham oportunidades de formação e apoia os projetos de inovação de grupos de docentes, a probabilidade de que se sintam mais satisfeitos aumenta" (MARQUESI, 2008, p. 122), refletindo-se diretamente na motivação à docência.

Argumenta-se que, ainda que na LDBEN 9.394/1996 (Lei de Diretrizes e Bases do Ensino Nacional - Brasil) esteja estabelecido que é direito do professor à formação continuada, essa formação deve ser entendida muito além do direito, ainda que não estabelecido de fato em políticas públicas de educação, mas sim como políticas de governo.

Isto é, a educação contínua na/da docência deve ser entendida como um dever de todo educador, visto que essa profissão tem como princípio básico o aprender e o ensinar do ser humano. E este está em constante desenvolvimento por toda a vida, sendo capaz de aprender em qualquer etapa, a qualquer tempo, respeitadas as individualidades de cada indivíduo. A responsabilidade docente é proporcional às necessidades e intencionalidade dos educandos, no que condiz com as devidas motivações pessoais.

Nesse percurso, a aprendizagem continua no mundo do trabalho e revela, muitas vezes, que a própria prática do fazer pedagógico precisa efetivar-se em uma crítica anterior à vivência entre os fazeres e saberes docentes. Mesmo porque "a área da vida adulta que a aprendizagem permeia mais persistentemente do que talvez outra é o trabalho" (CLAXTON, 2005, p. 221). Por isso, a experiência vivida, salientada por Tardif (2002), é a base das ações pedagógicas do professor. Cabe ressaltar que a possibilidade de refletir na ação, contrapondo-se aos saberes antes fundamentados, refere-se aos critérios e juízos do professor enquanto profissional e atuante em sua prática educativa. Isto é, enquanto sujeito de suas aprendizagens, o educador, e com sua própria leitura de vida, revela a prática educativa e sua concepção de ser humano. Esta a recompõe de forma significativa, sempre que possível e consciente, em uma nova dimensão humana e social.

Nisso tudo, considera-se oportuna a preocupação com diferentes abordagens metodológicas no que concerne às propostas de formação continuada para professores: há que se estabelecer um modelo de construção contínua, um modelo de aprendizagem social, com propostas relacionais de vivências dentro do ambiente de trabalho.

Esses espaços, constituídos e sistematizados dentro do ambiente educativo, podem compor as ações humanas na pessoalidade, no agir de cada pessoa, indicando e ativando a motivação pessoal, em que cada indivíduo se encontra 
e se identifica nas representações sociais e culturais do seu meio educacional. Esse autoconhecer-se pode ser entendido como ampliação de consciência, no sentido de o ser humano encontrar-se em sua subjetividade. E pode ser constituído na educação continuada pessoal, nas escolhas particulares, mas também na formação em grupo, dentro do ambiente educativo.

Sabe-se que, embora não existam receitas prontas, modelos universais ou métodos infalíveis para o combate do mal-estar e da desmotivação docentes, de acordo com Jesus (2004, p. 44),

a prevenção de muitas situações passa pela formação de professores, no sentido desta contribuir para que a prática profissional seja experienciada com satisfação e autoconfiança, encorajando a construção de um percurso profissional caracterizado pela motivação e pelo desenvolvimento pessoal e interpessoal, enquanto critérios fundamentais do bem-estar docente.

Portanto, uma educação continuada, voltada para o desenvolvimento humano, a partir de concepções reais e atuais sobre as qualidades pessoais e profissionais dos professores, pode proporcionar a satisfação e o bemestar profissional do docente e promover uma elevação no seu nível de motivação. Refletindo-se na pessoalidade de cada um, oferece possibilidades de trabalhar com o autoconhecimento, no sentido de atentar para as metas desejadas e caminhos para atingi-las. Conforme Jesus (2004, p. 50), "a motivação do professor é fundamental para que possa superar as dificuldades com que se confronta e realizar-se profissionalmente, mas deve ser consoante com os resultados que efetivamente consegue alcançar", no pressuposto da ampla dimensionalidade do indivíduo.

Nesse sentido, aponta-se para oficinas pedagógicas, realizadas a partir das necessidades dos professores, com as intencionalidades destes, no ambiente escolar, e com a participação de todos os envolvidos no lócus educativo, especialmente os pares e suas demandas de dificuldades apontadas pela diversidade e adversidade da esfera sociocultural. Para Antunes (2016), essa proposta referese a oficinas pedagógicas cooperativas. De modo que

[...] a prática de aprendizagens através de oficinas vem sendo cada vez mais difundida e exercitada, talvez pelos resultados positivos e pela efetivação dos objetivos elencados a cada nova proposta de aprendizagem. Percebe-se que a atuação humana ativa motiva o indivíduo a novas aprendizagens, bem como revela a possibilidade de refletir acerca de vivências (ANTUNES, 2016, p. 39).

Nesse propósito, a proposta de ação/reflexão do/ no trabalho docente, que vislumbre momentos de inter/ intra-relações, deve destacar-se como núcleo central de formação docente, com vistas ao autoconhecimento. Aprendizagem por meio de oficinas pode vislumbrar um autoconhecimento especialmente pela prática da ação-reflexão-ação, não só pela participação do/em grupo, ponto esse que pode ser o culminante do trabalho, mas inevitavelmente pela intencionalidade da reflexão individual que pode acontecer a cada momento proposto.

Antunes (2016) também alerta:

O agir no grupo e com o grupo durante uma proposta pedagógica de oficina, em uma dinâmica de resoluções de problemas, mobiliza a ação em conjunto. Pensar com o outro é, acima de tudo, partilhar as possíveis soluções para as dificuldades que possam se apresentar; nesse caso específico, o ambiente escolar e suas adversidades constantes (ANTUNES, 2016, p. 39).

Ainda de acordo com Vieira e Volquind (2002), "oficina é uma forma de ensinar e aprender, mediante a realização de algo feito coletivamente, é uma modalidade de ação onde necessita promover a investigação, a ação e a reflexão; combinar o trabalho individual e a tarefa socializada; garantir a unidade entre teoria e prática"; uma proposta de aprender com o outro, aprender juntos.

Outra autora, Cuberes (1989, p. 3), também esclarece que "oficina é um tempo e um espaço para aprendizagem; um processo ativo de transformação recíproca entre sujeito e objeto, um caminho com alternativas, com equilibrações que nos aproximam progressivamente do objeto a conhecer". Ou seja, aprendizagens significativas por vivências significativas entre os participantes.

Por isso, entre outras possibilidades possíveis de educação contínua, no caminho da aprendizagem coletiva por meio de oficinas, com o propósito de construção do trabalho pedagógico mais coerente com as necessidades do século XXI, entre outras obrigações de um ensino mais atualizado, justificam-se as oficinas pedagógicas cooperativas, através de um dos pilares da educação, de acordo com o relatório Jacques Delors (2003) para a UNESCO sobre a educação para o século XXI, o aprender a viver juntos.

Nesse contexto, enfatiza-se, então, que a educação contínua deve ser entendida como necessária especialmente na profissão docente e oportunizada no sentido de espaço pedagógico de aprendizagens significativas, dentro do espaço escolar, em atividades cooperativas com outros professores. Além disso, deve ser vivenciada em oficinas pedagógicas que pela experiência pessoal vivida efetivam-se em outros saberes docentes. Mesmo porque "os professores - talvez isso ocorra em todas as profissões - tendem a ser individualistas na sua atividade e têm receio em compartilhar desejos e frustrações" (MARQUESI, 2008 , p. 125). Por essa razão, indica-se muito mais 
atenção às propostas de formação a qualquer tempo, na carreira, com possibilidades de ações, especialmente na resolução de problemas, junto com os pares. Sobretudo, há que se questionar qual a necessidade de cada docente em cada espaço educativo.

Nesse propósito, "o autoconhecimento traduz uma possibilidade de conhecimento pessoal; conhecedor da identidade própria, com possibilidade de lidar com as dificuldades e adversidades que fazem parte do amadurecimento humano, buscando a transformação pessoal e a posterior contribuição na construção de ambientes sociais mais dignos, saudáveis e felizes para todos" (ANTUNES, 2016, p. 88).

É necessário, especialmente, o professor disponibilizar-se ao aprender sempre e, antes disso, conceber, acima de tudo, o desenvolvimento humano como um processo em toda a existência de vida, conforme já apontado. Sendo assim, uma experiência que vem sendo efetivada e destacada são as oficinas pedagógicas cooperativas (ANTUNES, 2012), com propostas de atividade entre e com os pares, destinadas ao autoconhecimento, de modo a abarcar as motivações intrínsecas a partir dos motivos externos do ofício de $\mathrm{Ser}$ Professor. Práticas que proporcionam ao docente uma possibilidade de autorrealização.

De certo modo, "as relações com os colegas, que às vezes também são amigos, constituem uma estrutura protetora que ajuda, muitas vezes de forma decisiva, a manter a estabilidade emocional e o bom ânimo na profissão. Com eles, compartilhamos iniciativas, projetos, problemas, frustrações e satisfações" (MARQUESI, 2008, p. 125). No mesmo sentido, "viver em sociedade é fundamental para o desenvolvimento e o amadurecimento pessoal. Através das inter-relações o indivíduo se constitui e constrói sua identidade" (ANTUNES, 2016, p. 38), podendo, outrossim, configurar um autoconceito real e positivo na intrarrelação.

Marquesi (2008) ainda ratifica essas situações e a necessidade de ações de formação, dentro do propósito da formação em serviço, como uma situação nada simples de ser realizada. Ele alerta que "é necessário estar atento para evitar que essas relações se afastem da dinâmica geral da escola e do contato com o resto dos colegas, ou que se transformem em grupos de pressão que possam distorcer o funcionamento da escola" (MARQUESI, 2008, p. 125).

Essas e outras situações requerem uma atenção especial acerca da proposta de formação, com objetivos claros e específicos quando da docência, seja nela, com ela ou para ela. Antes, porém, da formação em grupo e no lócus escolar, há que se estabelecer as razões e os propósitos de pertencimento ao grupo de professores, quando da necessidade de formação e suas possibilidades acadêmicas, políticas, ou de cunho pessoal e privado para cada instituição. Sobretudo, Marquesi (2008, p. 126) enfatiza que

é preciso que realizemos nossa atividade com suficiente
distância profissional, para mantermos o equilíbrio e
não nos esgotarmos no empenho imediato. Mas também
é necessário, ao mesmo tempo, viver com dedicação
e entusiasmo o trabalho em que estamos envolvidos.
Para isso, precisamos perguntar continuamente aos
mesmos para que e por que educamos e buscar com
afinco uma resposta que nos ajude a manter nosso
compromisso com a educação (MARQUESI, p. 126).

Ou seja, acredita-se que, nesse sentido, destacado pelo autor acima, e em outras possibilidades, as oficinas de autoconhecimento podem representar uma estratégia de ação daquilo que pode ser feito em termos de educação contínua de professores, contribuindo para o desenvolvimento, aprendizagem e realização profissional dos professores. De modo mais esclarecedor, uma "Educação Continuada voltada para o desenvolvimento de concepções realistas sobre as qualidades pessoais e profissionais, além de proporcionar a satisfação e o bem-estar profissional do docente, promove uma elevação no seu nível de motivação, bem como do próprio estudante" (ANTUNES; PLASZEWSKI; DECKER; SILVA, 2017, p. 46).

Sabe-se que o paradigma de educação continuada para professores é uma proposta relativamente nova. Muitos educadores, principalmente aqueles que já estão em final de carreira, não acreditam ser necessária a educação constante e permanente na docência. Há pouco tempo, o entendimento era de que o Ser Professor se estabelecia na formação inicial e nada mais era necessário, especialmente porque o conhecimento era encontrado em enciclopédias, em grandes estantes ou bibliotecas. Hoje, com a velocidade das informações e com o avanço dos estudos científicos, nada mais devido que uma atualização constante do professor.

Nesse pensar, "a educação continuada destaca-se como um instrumento por meio do qual os indivíduos buscam manter-se atualizados numa sociedade que muda muito mais rapidamente do que em décadas passadas", afirma Lomônaco (2012, p. 7). Portanto, a atualização é necessária no sentido de adaptar-se constantemente às necessidades e potencialidades dos alunos, nos mais diferentes ambientes educativos, compostos pela diversidade de cada indivíduo ali presente.

Sabe-se que algumas ações governamentais foram disponibilizadas e realizadas em diferentes níveis de ensino, com distintas organizações e realidades institucionais, para além da diversidade de contextos socioculturais em cada meio educativo e com suas adversidades culturais e estruturais. Como exemplos, o 
Pacto Nacional pelo Fortalecimento do Ensino Médio (PNEM) e o Pacto Nacional pela Alfabetização na Idade Certa (PNAIC), entre outras ações.

Ainda assim, são propostas importantes na medida em que oportunizam o trabalho cooperativo de aprendizagens entre os pares, com possibilidades de repensar a prática educativa e com vistas à solução de problemas e conflitos do dia a dia da profissão. Além disso, vislumbram uma educação contínua integralizadora das necessidades pessoais e do grupo de docentes no ambiente educativo.

\section{A FORMAÇÃo CONTINUADA EM PESQUISA}

Formação de professores é um campo complexo e também profícuo de investigações. Muitas são as propostas, pesquisas, livros e trabalhos acadêmicos publicados no que se refere à formação continuada de professores, ainda que esta não esteja de fato efetivada no dia a dia do professor, neste país, seja como direito do docente, seja como dever do estado enquanto garantia em lei.

Ao docente, refere-se à busca constante e pessoal no percurso da professoralidade sempre em construção. Tardif (2002, p. 64) destaca que "o saber profissional está, de certo modo, na confluência entre várias fontes de saberes provenientes da história de vida individual, da sociedade, da instituição escolar, dos outros educativos, dos lugares de formação, etc".

Nesse mesmo sentido, Nóvoa (1999, p. 16) corrobora ao afirmar que "a natureza do saber pedagógico e a relação dos professores ao saber constituem um capítulo central da história da profissão docente". Por isso, a necessidade individual de conceber a educação continuada ao longo da vida, indubitavelmente ao longo da carreira docente.

Assim, entende-se que a formação está vinculada ao desejo de buscar novas e melhores formas de ensinar, superar impasses e compreender o que é ser professor do coletivo - interpessoal, ao individual - intrapessoal; um docente em contínua construção. Tardif (2002, p. 249) afirma: "Tanto em suas bases teóricas quanto em suas consequências práticas, os conhecimentos profissionais são evolutivos e progressivos e necessitam, por conseguinte, de uma formação contínua".

Para atingir tais objetivos e metas de vida na escolha do Ser Professor, incluem-se como componentes formativos outros espaços e tempos de formação, além dos saberes acadêmicos, da formação inicial ou da busca por autoconhecimento. Para Nóvoa (1992, p. 27), a

formação pode estimular o desenvolvimento profissional dos professores, no quadro de autonomia contextualizada da profissão docente. Importa valorizar paradigmas de formação que promovam a preparação de professores reflexivos, que assumam a responsabilidade do seu próprio desenvolvimento profissional e que participem como protagonistas na implementação de políticas educativas.

No que concerne a ações específicas de formação contínua, este texto destaca o Pacto Nacional pelo Fortalecimento do Ensino Médio (PNEM), que entre outras propostas governamentais foi uma possibilidade de formação continuada, realizada dentro do ambiente escolar, em escolas da rede pública estadual de ensino, em nível nacional. Proposta realizada em cooperação entre Secretarias Estaduais de Educação (SEDUC), Coordenadorias Regionais de Educação (CREs), nos municípios participantes, professores da rede estadual atuantes no Ensino Médio e universidades federais. Cabe ressaltar que as universidades estiveram à frente do processo de formação, com a atuação de seus professores e parceiros, realizando oficinas de formação. Em outras palavras, o PNEM foi uma

iniciativa, um programa político de governo, que esteve em consonância com as Diretrizes Curriculares Nacionais para o Ensino Médio DCNEM - de 2012, as quais indicavam o início de significativas mudanças na estrutura curricular e pedagógica na etapa final da Educação Básica - EB - brasileira: o Ensino Médio. Especialmente no Rio Grande do Sul, tais Diretrizes embasaram a reforma do Ensino Médio Politécnico ${ }^{2}$ em 2012 e a proposta da formação de educadores através do PNEM estabelece conformidade a essa reestruturação, pois o formato das ações de formação foi, justamente, idealizado na perspectiva interdisciplinar onde o trabalho, a pesquisa e a prática social são tidos como princípios educativos, os mesmos princípios da reforma (ANTUNES; GUILHERME; SANTOS, 2017, p. 52).

Assim, a partir da Portaria Ministerial n. 1.140, de 22 de novembro de 2013, organizou-se em duas etapas de estudos, num total de 200 horas de formação, entre 2014 e 2015. A universidade realizava, através de oficinas e seminários, formação com supervisores regionais (indicados pelas CREs), e em alguns casos, como no Rio Grande do Sul, juntamente com formadores (coordenadores pedagógicos das escolas participantes). Seguindo esse percurso, os formadores realizavam nas escolas, com os professores do Ensino édio, os estudos

\footnotetext{
2 A reforma do EM no Rio Grande do Sul, que instituiu o Ensino Médio Politécnico, traz, dentre outras mudanças, a flexibilização da carga horária da etapa para a introdução do componente curricular "Seminário Integrador", que aplica a pesquisa como princípio metodológico, com carga horária gradual entre os três anos. Tal componente pretende introduzir o trabalho de pesquisa no EM como uma possibilidade de aperfeiçoamento da etapa e também como forma de os estudantes vislumbrarem a entrada no ensino superior.
} 
e trabalhos reflexivos sobre as temáticas indicadas em cadernos de formação, disponibilizados pelo programa, com o objetivo de renovar práticas pedagógicas, que mobilizassem os alunos, jovens do século XXI.

Com essas e outras tantas mudanças no que concerne às atividades docentes, há que se estabelecer ações de formações permanentes de educadores. Conforme já destacado: uma Educação Continuada que contemple, muito além dos métodos e didáticas entre processos de ensino e de aprendizagem, uma ação pessoal do aprender ao longo da vida, pela qual educadores possam buscar seus desejos constantes de autoconhecimento com vistas à autorrealização. O documento Global Report on Adult Learning and Education, da UNESCO (2009), é enfático na importância da Educação Continuada (lifelong learning and education) para indivíduos e que Estados tem que assumir essa pauta com maior responsabilidade (ANTUNES; GUILHERME; SILVA, 2017, p. 52-53).

Considera-se que a aprendizagem contínua e a troca de experiências em grupos entre os professores são elementos importantes para caracterizar uma educação continuada de professores. Tudo isso aponta o olhar para os espaços e tempos de formação de uma maneira mais abrangente, não restrita ao espaço escolar ou acadêmico, baseada na valorização do trabalho de equipe, da partilha e da parceria. Nisso, Portal (2002, p. 15) adverte que "Ser Professor está hoje a exigir um novo perfil, uma nova postura, caracterizada por uma atitude: pró-ativa, crítica, empreendedora, com habilidades de socialização, facilidades em trabalhar em e com equipes [...]" (grifo do autor).

Nesse contexto, este texto aponta algumas reflexões sobre o programa enquanto política de formação continuada, dentro de um pequeno recorte dos resultados de pesquisa num total de 400 questionários entregues, realizado após o término da II Etapa do PNEM, em junho de 2015, no Seminário Estadual, realizado no RS, onde estiveram presentes as seis universidades federais participantes do pacto neste estado (UFRGS, UFPel, FURG, UFSM, UFFS, UNIPAMPA).

Como resultados parciais dessa pesquisa, destaca-se que a quase totalidade dos sujeitos entrevistados, referindo-se especificamente ao programa, apontam que o PNEM foi "ótima oportunidade para melhorar a atuação na sala de aula. Com as formações do pacto fica mais fácil realizar o planejamento em conjunto, discutir temas específicos sobre onde a escola está inserida, e isso torna o trabalho enriquecedor, pois o professor pode repensar sua prática em sala de aula". (Sujeito 5 - 16 $\underline{\text { a }}$ CRE)

A opinião de alguns professores participantes indica que a proposta do PNEM, enquanto política de formação continuada, especialmente no ambiente educativo, atingiu seu objetivo de proporcionar atualização aos professores: "A formação continuada faz parte da minha vida pessoal e profissional. Enquanto política pública, é uma ação importante de valorização profissional, um estímulo para melhorar as práticas pedagógicas. Seu principal resultado é a formação integral" (Sujeito 7 - 7a CRE). Ou seja, "cada experiência educativa pode provocar diversas aprendizagens" (tradução livre), afirma Undurraga Infante (2004, p. 21).

Outro sujeito também afirmou acerca da mesma proposta: "Achei que não iria ver como política pública algo que trouxesse e torna toda a problemática in loco. O pacto é a formação continuada que contempla em seu 'pacote' a essência da educação, enquanto formação continuada" (Sujeito 7 - 1․ CRE). Por essa afirmação, o participante talvez considere que a desvalorização da profissão docente esteja evidenciada na falta de políticas públicas de educação, condizentes com as leis e necessidades dos professores.

Mesmo assim, Zabalza (2004, p. 78), ressalta que "alguns eixos importantes na construção da identidade docente devem ser considerados, tais como "a percepção do seu papel e a hierarquia nos propósitos; os centros de interesse pessoal; a satisfação que o trabalho proporciona; a carga de trabalho que implica a docência, a saúde, o stress e a autonomia", especialmente em propostas de estudo e formação no ambiente educativo. O que indicam, também, as palavras de outro professor: "A formação continuada é importantíssima na escola. O PNEM nos mostrou que é possível essa formação acontecer nas escolas e no horário do professor" (Sujeito $\left.5-6^{\underline{a}} \mathrm{CRE}\right)$.

Outros participantes também afirmaram:

\begin{abstract}
“O PNEM, enquanto política pública, foi importante, pois proporcionou um meio de formação e linguagem uniforme quanto à qualidade e às metas para a educação do Brasil" (Sujeito11 - 2a CRE).

"Foi a primeira e única política de formação continuada na própria escola para fortalecer o trabalho pedagógico. Foi muito estudo, e houve mudanças positivas e construtivas na percepção de uma escola melhor" (Sujeito $21-3$ 를 CRE).

"Avalio como positiva a proposta. A formação continuada precisa ser incentivada. Como nem todos os profissionais da educação compreendem a importância de se atualizar, então é preciso que o poder público interfira, pensando no bem da educação como um todo" (Sujeito $11-3 \underline{\text { CRE}) . ~}$
\end{abstract}

No entanto, ainda há muito para ser pensado, discutido e construído coletivamente, quando se quer uma nova cultura paradigmática de educação continuada para educadores. É muito provável que a epistemologia dos conceitos que envolvem tais intencionalidades de 
mudanças precise ser abarcada para que o professor também perceba a formação como um direito pessoal, não somente como um dever a todo educador. Pois "a aprendizagem não é um fenômeno exclusivo dos contextos educativos, senão, mais ainda, parte do funcionamento vital do ser humano" (tradução livre) (UNDURRAGA INFANTE, 2004, p. 21).

Enfim, nesse sentido de formação continuada, Portal e Franciscone $(2007$, p. 560) enfatizam que "é fundamental que ultrapassemos o conceito primário de Educação Continuada, preocupada apenas com as competências intelectuais do homem para viver no mundo da informação".

Por tudo isso, e a partir dessas afirmações dos participantes, afirma-se que a formação contínua de professores deve estar no caminho da formação autoformação, com indicativos constantes de reflexões - e da autorreflexão da/na prática educativa. De modo que os momentos de vivência - convivência entre os pares devem se constituir em propósitos de desenvolvimento pessoal e do grupo, num continuum, ao longo da vida. A educação continuada precisa dar significado e motivos pessoais às ações diárias do indivíduo, especialmente no espaço de ação docente, no ambiente escolar.

\section{CONSIDERAÇÕES REFLEXIVAS}

A escolha do Ser Professor, que pode estar de certo modo inconsciente ainda no início da carreira, é edificada desde a infância e tem, inevitavelmente, seu grande desafio quando o acadêmico licenciando adentra o ambiente educativo, muitas vezes pela primeira vez, nos estágios obrigatórios da formação inicial. Infelizmente, muitos alunos nos cursos que habilitam para a profissão docente, quando se deparam com o ambiente escolar pela primeira vez, sentem-se desanimados com a realidade encontrada, seja ela de caráter estrutural, de conjunturas socioculturais, de insegurança pessoal, entre outras, seja pela desmotivação que os docentes transpassam no ambiente educativo.

Pois aprender a conviver é saber respeitar a individualidade e a subjetividade de constituições pessoais, respeitando as diferenças para desenvolver projetos solidários e cooperativos em busca de objetivos comuns. Por meio da solidariedade e da busca pela compreensão mútua, os indivíduos se edificam na diversidade, descobrindo o outro como ser humano, também com potencialidade positivas.

O agir no grupo e com o grupo durante uma proposta pedagógica de oficina, em uma dinâmica de resoluções de problemas, mobiliza a ação em conjunto. Pensar com o outro é, acima de tudo, partilhar as possíveis soluções para as dificuldades que possam se apresentar; nesse caso específico, o ambiente escolar e suas adversidades constantes. Ainda assim, parece que alguns professores não conseguem conceber a urgência permanente da aprendizagem ao longo da vida, talvez pela internalização de conceitos acerca do desenvolvimento humano, muito aquém do conhecimento atualizado que adentram as instituições escolares.

Enfatiza-se, mais uma vez, que o ato de aprender perpassa por toda a existência humana, inevitavelmente, quando em sociedade, ainda que no contexto social de uma única instituição institucionalizada de educação. E a prática de aprendizagens através de oficinas vem sendo cada vez mais difundida e exercitada, talvez pelos resultados positivos e pela efetivação dos objetivos elencados a cada nova proposta de aprendizagem, pois a atuação ativa na proposta de oficinas também pode evidenciar motivos pessoais intrínsecos através do pensar e agir com intencionalidade pessoal.

Aliás, a aprendizagem em oficinas pedagógicas cooperativas (ANTUNES, 2012, 2016) revela-se em um tempo e em um espaço privilegiado para a (con)vivência, para a reflexão, para a ação em grupo, para a partilha de propostas pedagógicas e também para a participação no sentido de constituir-se educador; um tempo propício para a aprendizagem pessoal, para o autoconhecimento. Oficinas pedagógicas representam um tempo para pensar, refletir, sentir e agir!

$\mathrm{Ou}$, ainda, oficinas pedagógicas constituem-se em uma estratégia de trabalho em grupo voltada para a busca da solução de problemas, especialmente quando realizadas no ambiente escolar, nas/pelas intencionalidades dos indivíduos envolvidos nos processos de ensino e de aprendizagem. Cabe ressaltar que outras propostas de formação continuada são apresentadas por diferentes autores, ou seja, as oficinas pedagógicas cooperativas constituem-se em um modelo, em uma proposta que vem se estabelecendo com importante espaço de aprendizagem. Mas alerta-se que as oficinas não são uma possibilidade de autoajuda, com indícios de superficialidade em ações e reflexões, mas buscam revelar as internalizações pessoais de cada docente, através do caminho do autoconhecimento.

Contudo, o professor, que outrora, talvez ainda na infância, decidiu-se pela profissão docente, habilitou-se na academia, no momento da formação inicial, sobretudo, edifica-se no dia a dia da docência. Mas, de modo renovador em relação às práticas pedagógicas e às suas necessidades e especificidades, deve conceber a formação continuada, de modo a buscar uma educação contínua ao longo da vida. Essa proposta paradigmática de educação continuada deve estar embasada em modelos de vivência em grupo, a partir de experiências pessoais, especialmente com possibilidades de realização no lócus escolar. 
Assim, nesse propósito, este texto aponta para a experiência cooperativa em oficinas pedagógicas, de modo a oportunizar diferentes e significativas aprendizagens no ambiente escolar, com os pares, ou seja, com os professores inseridos no mesmo ambiente educativo. $\mathrm{O}$ objetivo, entre outros, é constituir propostas e alternativas às necessidades e à resolução de problemas no dia a dia escolar.

Sabe-se que algumas propostas de formação contínua são ofertadas, sejam estas, nas mais distintas possibilidades, de caráter privado ou público. No entanto, há que se estabelecer o direito a uma educação contínua que atente às necessidades de todo educador, especialmente neste país.

Enfim, ressalta-se que o docente e sua formação estão imbricados no processo de desenvolvimento pessoal, que devem perpassar as questões, desde o porquê da escolha do Ser Professor até o tipo de professor que deseja ser, o tipo de sociedade que vai ajudar na formação, ainda, ou o tipo de professor que os alunos esperam encontrar no dia a dia da ação educativa, em qualquer instância de ensino.

\section{REFERÊNCIAS}

ANTUNES, Denise Dalpiaz. Oficinas Pedagógicas Cooperativas: a motivação docente na formação continuada. Curitiba: Editora CRV, 2016.

ANTUNES, Denise Dalpiaz. Oficinas Pedagógicas de Trabalho Cooperativo: uma proposta de motivação docente, 2012. Tese (Doutorado em Educação) - Faculdade de Educação da Pontifícia Universidade Católica do Rio Grande do Sul, Porto Alegre, 2012.

ANTUNES, Denise Dalpiaz; GUILHERME, Alexandre Anselmo; SILVA, Lucas Rech. Concepções, desafios e avanços na Educação continuada de professores. In: ANTUNES, Denise Dalpiaz; PLASZEWSKI, Helenara. Educação continuada: um paradigma em diferentes ações, distintas experiências e significativos contextos. Porto Alegre: Evangraf, 2017.

ANTUNES, Denise Dalpiaz; PLASZEWSKI, Helenara; DECKER, Dionlei Alves; SILVA, Lucas Rech. Formação Continuada de Professores no Locus Escolar. In: ANTUNES, Denise Dalpiaz; PLASZEWSKI, Helenara. Educação continuada: um paradigma em diferentes ações, distintas experiências e significativos contextos. Porto Alegre: Evangraf, 2017.

BOURDIEU, Pierre. Escritos de educação. Maria Alice Vergueiro e Afranio Catani (Org.). 14. ed. Petrópolis: Vozes, 2013.

CLAXTON, Guy. O desafio de aprender ao longo da vida. Porto Alegre: Artmed, 2005.

CUBERES, Maria Teresa Gonzalez. El taller de los talleres. Buenos Aires: Estrada, 1989.

DELORS, Jacques. Educação: um tesouro a descobrir. Relatório para a Unesco da Comissão Internacional sobre a Educação para o Século XXI. 8. ed. São Paulo: Cortez, 2003.
FREITAS, A. S. Os desafios da formação de professores no século XXI: competências e solidariedade, In: FERREIRA, A. T. B. (Org.). Formação continuada de professores. Belo Horizonte: Autêntica, 2007.

JESUS, Saul Neves de. Psicologia da Educação. Coimbra: Quarteto Editora, 2004.

LOMÔNACO, José Fernando B. Apresentação à edição brasileira. In: LÓPEZ-BARAJAS ZAYAS, Emilio. O paradigma da educação continuada. Porto Alegre: Penso Editora, 2012.

MARQUESI, Álvaro. O bem-estar dos professores. Porto Alegre: Artmed, 2008.

MASLOW, Abraham Harold. Introdução à psicologia do ser. Tradução de Álvaro Cabral. Rio de Janeiro: Eldorado, 1970.

MIZUKAMI, M.G.N. Ensino as abordagens do processo. São Paulo: E.P.U., 2007. 119 p.

MOSQUERA, Juan José Mourino. Vida adulta: personalidade e desenvolvimento, 3. ed. Porto Alegre: Sulina, 1987.

MOSQUERA, Juan José Mourino. Vida adulta: visão existencial e subsídios para teorização. Educação, Porto Alegre, n. 5, p. 94-112, 1982.

MOSQUERA, Juan José Mourino. As ilusões e os problemas da vida. Porto Alegre: Sulina, 1979.

NÓVOA, António. Novas disposições dos professores: a escola como lugar da formação, 2003. Disponível em: <http:// repositorio.ul.pt/bitstream/10451/685/1/21205 ce.pdf>. Acesso em: 22 de nov. 2017.

NÓVOA, António. A formação de professores e profissão docente. In: NÓVOA, A. (Coord.). Os professores e sua formação. Lisboa: Dom Quixote, 1992.

NÓVOA, António. O passado e o presente dos professores. In: NÓVOA, António. (Org.). Profissão professor. 2. ed. Porto: Porto, 1999.

PORTAL, Leda Lísia Franciosi. O professor e o despertar de sua espiritualidade. In: ENRICONE, Délcia (Org.). Ser professor. EDIPUCRS: Porto Alegre, 2002. p. 109-124.

PORTAL, Leda Lísia Franciosi; FRANCISCONE, Fabiane. Contribuições da educação continuada na construção da inteireza do ser. Educação, Porto Alegre, 2007, n. 3 (63), p. 557-569, set./dez. 2007.

TARDIF, Maurice. Saberes docentes e formação profissional. Petrópolis/RJ: Vozes, 2002.

UNDURRAGA INFANTE, Consuelo. Como aprenden los adultos? Ediciones Universidad Católica de Chile, Santiago, 2004.

VIEIRA, Elaine; VOLQUIND, Lea. Oficinas de ensino: O quê? Por quê? Como? 4. ed. Porto Alegre: EDIPUCRS, 2002.

ZABALZA, Miguel Ángel. O ensino universitário: seu cenário e seus protagonistas. Porto Alegre: Artmed, 2004.

Recebido em 22-01-2018

Aprovado em 09-03-2018. 